\title{
Effect of cold rolling on the oxidation resistance of T91 steel in oxygen-saturated stagnant liquid lead-bismuth eutectic at $450^{\circ} \mathrm{C}$ and
}

\author{
$550^{\circ} \mathrm{C}$ \\ Hong Dong ${ }^{\mathrm{a}}$, Zhongfei Yea ${ }^{\mathrm{a}}$ Pei Wang ${ }^{\mathrm{a}}$, Dianzhong Li ${ }^{\mathrm{a}}$, Yutuo Zhang ${ }^{\mathrm{b}}$, Yiyi Li ${ }^{\mathrm{a}}$ \\ ${ }^{\text {a}}$ Shenyang National Laboratory for Materials Science, \\ Institute of Metal Research, Chinese Academy of Sciences, \\ 72 Wenhua Road, Shenyang 110016, China \\ ${ }^{\mathrm{b}}$ Shenyang Ligong University \\ 6 Nanping Road, Shenyang 110159, China
}

\begin{abstract}
The compatibility of T91 steels having different preparation processes with oxygen-saturated stagnant lead-bismuth eutectic have been investigated at $450^{\circ} \mathrm{C}$ and $550^{\circ} \mathrm{C}$. It is found that cold rolling decreases the thickness of the oxide scale of T91 steel by forming a continuous enhanced $\mathrm{Cr}$-rich belt in the inner oxide layer next to the internal oxidation zone, which is attributed to the rapid diffusion of $\mathrm{Cr}$ induced by numerous non-equilibrium grain boundaries and migrating dislocations.
\end{abstract}

Keywords: Lead-bismuth eutectic, martensitic steel, cold rolling, non-equilibrium grain boundary, migrating dislocation

*Corresponding author: Tel.+86-24-83970106, Fax. +86-24-83970106, Email. pwang@imr.ac.cn (P. Wang) 


\section{Introduction}

Lead-bismuth eutectic (LBE) has been a promising candidate material for the coolant in accelerator-driven system (ADS) and Lead-cooled fast reactor (LFR), as well as the spallation target in ADS. However, the liquid LBE is severely corrosive to structural materials at high temperature, which presents a critical challenge in the use of LBE in advanced nuclear systems [1]. Compared with austenitic steels, ferritic/martensitic (F/M) steels have a superior irradiation resistance [2] and lower Ni content that has a high solubility in LBE. Therefore, T91 martensitic steel has been selected as one of promising candidate structural materials in ADS and LFR.

Extensive investigations have been conducting to understand the oxidation behavior of T91 steel in liquid LBE [3-7]. Most of T91 samples in these literatures were forged rather than cold-rolled. However, some of the components, which directly contact with the high temperature liquid LBE in ADS and LFR, are produced by cold rolling. Therefore, it is of importance to investigate the effect of cold rolling on the oxidation resistance of T91 steel in LBE. In fact, several researches have shown the influence of cold rolling on the oxidation resistance of austenitic steels in LBE [8-10]. It has been reported that cold rolling improved the oxidation resistance of austenitic steel due to the formation of a protective oxide layer, which was caused by enhancing the $\mathrm{Cr}$ diffusion through structural transformation [8] or grain refinement [9]. Nevertheless, it has also been reported that cold rolling aggravated the oxidation resistance of austenitic steel because the increase in dislocation density induced by cold rolling accelerated the $\mathrm{Cr}$ and $\mathrm{Ni}$ dissolution into LBE [10]. The contrary conclusions for 
austenitic steels indicate the complex mechanism behind the experimental results. Compared with austenitic steel, the original density of dislocation in T91 steel is much higher [11], therefore, the effect of dislocations induced by cold rolling on oxidation resistance is uncertain. Additionally, there is no deformation-induced phase transformation during cold rolling in T91 steel. Therefore, although the oxidation behavior of cold-worked austenitic steel in LBE has been studied, the effect of cold rolling on oxidation resistance of ferritic-martensitic steel, such as T91 steel, in LBE remains unclear.

To address this concern, the compatibility of T91 steels having different preparation processes with liquid LBE have been investigated in this work. By comparing the oxidation resistance of different samples, the mechanism of cold rolling influencing the oxidation resistance of T91 steel has been analyzed.

\section{Experiments}

The investigated T91 steel with the composition of Fe-0.09C-0.48Si-0.53Mn-8.94Cr-0.93Mo-0.19V-0.09Nb-0.04N (wt.\%) was prepared by vacuum induction melting. After forging at $1150-850^{\circ} \mathrm{C}$ three kinds of samples with different processing technology were prepared. The first sample was normalized at $1050^{\circ} \mathrm{C}$ for $1 \mathrm{~h}$ and tempered at $760^{\circ} \mathrm{C}$ for $1 \mathrm{~h}$ (called tempered sample), which is similar to the heat-treatment used in industry and other literatures. The second sample was only normalized at $1050^{\circ} \mathrm{C}$ for $1 \mathrm{~h}$ (called normalized sample). The third sample was used to simulate the fabrication process of thin-wall tubes [12-13] (called cold-rolled sample). It was first hot rolled at $1150^{\circ} \mathrm{C}$, resulting in a $67 \%$ reduction in 
thickness. Then, the hot-rolled plate was cold rolled in three passes to fabricate cold-rolled sheet from $5 \mathrm{~mm}$ to $1.2 \mathrm{~mm}$ in thickness. Moreover, the intermediate heat treatment (tempering at $760^{\circ} \mathrm{C}$ for $1 \mathrm{~h}$ ) was carried out after the first two passes of cold rolling. Finally, the cold-rolled $1.2 \mathrm{~mm}$ sheet was normalized at $1050^{\circ} \mathrm{C}$ for $1 \mathrm{~h}$ and tempered at $760^{\circ} \mathrm{C}$ for $1 \mathrm{~h}$.

The isothermal oxidation tests in oxygen-saturated stagnant $\mathrm{LBE}$ at $450^{\circ} \mathrm{C}$ and $550^{\circ} \mathrm{C}$ were conducted in an atmosphere controlled tube furnace with duration up to $2000 \mathrm{~h}$ (normalized samples were tested only at $550^{\circ} \mathrm{C}$ ). During the experiment $\mathrm{Ar}+5 \% \mathrm{O}_{2}$ gas is filled into the tube furnace as the cover gas. The liquid LBE was oxygen-saturated during the whole oxidation process as indicated by the presence of red $\mathrm{PbO}$ particles on the liquid metal surface. According to [14], the oxygen concentration in the liquid LBE is $3.14 \times 10^{-4}$ wt. $\%$ at $450^{\circ} \mathrm{C}$ and $1.17 \times 10^{-3}$ wt. $\%$ at $550^{\circ} \mathrm{C}$. After oxidation, the thickness and elements distribution of oxide layer were analyzed by scanning electron microscope (SEM), electron probe microanalysis (EPMA). The microstructures of three kinds of samples before and after oxidation experiment were observed by SEM and transmission electron microscopy (TEM). In addition, high-resolution transmission electron microscopy (HRTEM) was used to investigate the grain boundaries (GBs) in both cold-rolled and normalized samples.

\section{Results and discussions}

Figure 1 shows the statistical thickness of the oxide layer (including outer layer and inner layer) on $\mathrm{T} 91$ steel after being exposed to $\mathrm{LBE}$ at $450^{\circ} \mathrm{C}$ and $550^{\circ} \mathrm{C}$ for different times. As the temperature and exposure time increase, the thickness of oxide layers on 
the three samples increases. More importantly, the cold-worked sample has the thinnest oxide layer among the three samples, indicating a better oxidation resistance than tempered and normalized samples.
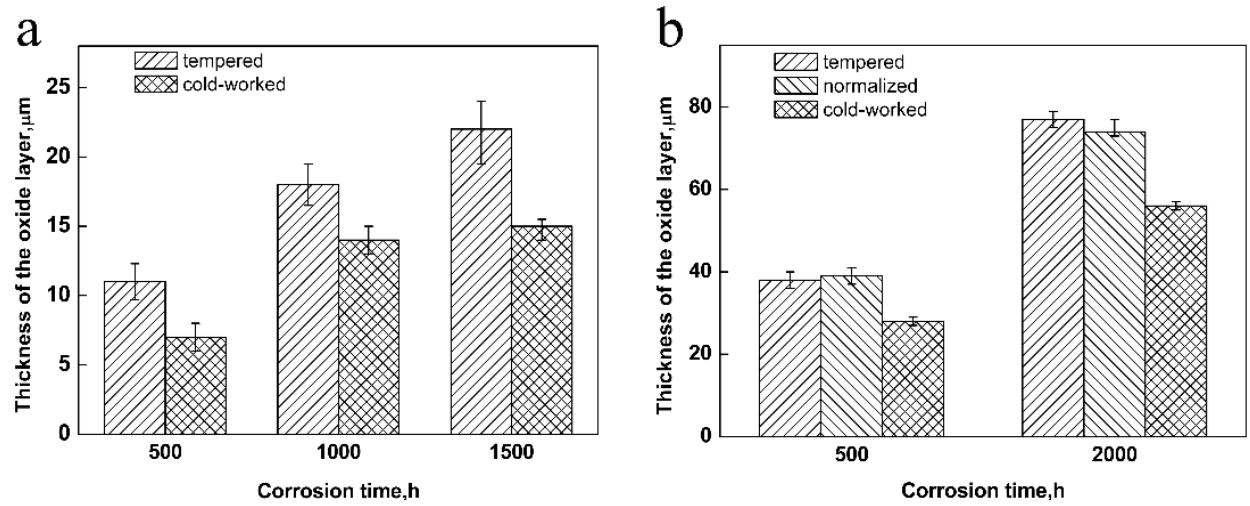

Fig. 1 The thickness of oxide layers after oxidation tests in oxygen-saturated stagnant LBE (a) at $450^{\circ} \mathrm{C}$, (b) at $550^{\circ} \mathrm{C}$

Figure 2 shows SEM-BSE, EPMA images of oxide layers on different samples after $550^{\circ} \mathrm{C} \times 500 \mathrm{~h}$ oxidation (normalized and tempered samples have the similar elements distribution, therefore, only the EPMA results of tempered sample are shown). As Fig. 2a-c show, all samples have a duplex oxide layer and an internal oxidation zone (IOZ) [4-5]. The outer oxide layer is mainly composed of magnetite $\mathrm{Fe}_{3} \mathrm{O}_{4}$ [4-5], which grows on the LBE/outer layer interface toward LBE. The inner oxide layer is $\mathrm{Fe}-\mathrm{Cr}$ spinel, which grows on the IOZ/inner layer interface into matrix [6]. Obviously, the oxide layer on cold-worked sample is thinner than those on the other two samples. Moreover, the growth frontier of inner layer is wavy in tempered and normalized samples, in contrast, it is straight in cold-worked sample (as arrows indicated in Fig. 2a-c). It is worth noting that a continuous Cr-rich belt, which has much higher $\mathrm{Cr}$ content than other area of the inner oxide layer, exists in the inner layer next to the IOZ in cold-worked sample (Fig. 2e). However, for tempered and normalized samples, 
although there are also some $\mathrm{Cr}$-rich points, which has higher $\mathrm{Cr}$ content than other area of the inner layer, in the inner layer, these Cr-rich points are scattered and discontinuous (Fig. 2h). In order to distinguish the Cr-rich belt and point from the other area of the Fe-Cr spinel inner layer, they are termed as enhanced $\mathrm{Cr}$-rich belt and enhanced Cr-rich point, respectively.

According to the available space model, the growth rate of oxide scales is controlled by iron cation diffusion from base metal to the oxide/LBE interface [7]. It has been confirmed that a higher $\mathrm{Cr}$ content in the $\mathrm{Fe}-\mathrm{Cr}$ spinel can lower the iron diffusion [15]. Consequently, the presence of the continuous enhanced $\mathrm{Cr}$-rich belt in cold-worked sample reduces the Fe diffusion rate, which decreases the growth rate of oxide layers and improves its oxidation resistance. By contrast, the scattered and discontinuous enhanced Cr-rich points in tempered and normalized samples only retard the diffusion of Fe locally, which induces the diverse diffusion rate of iron at different area and curved growth frontier of inner layer. 


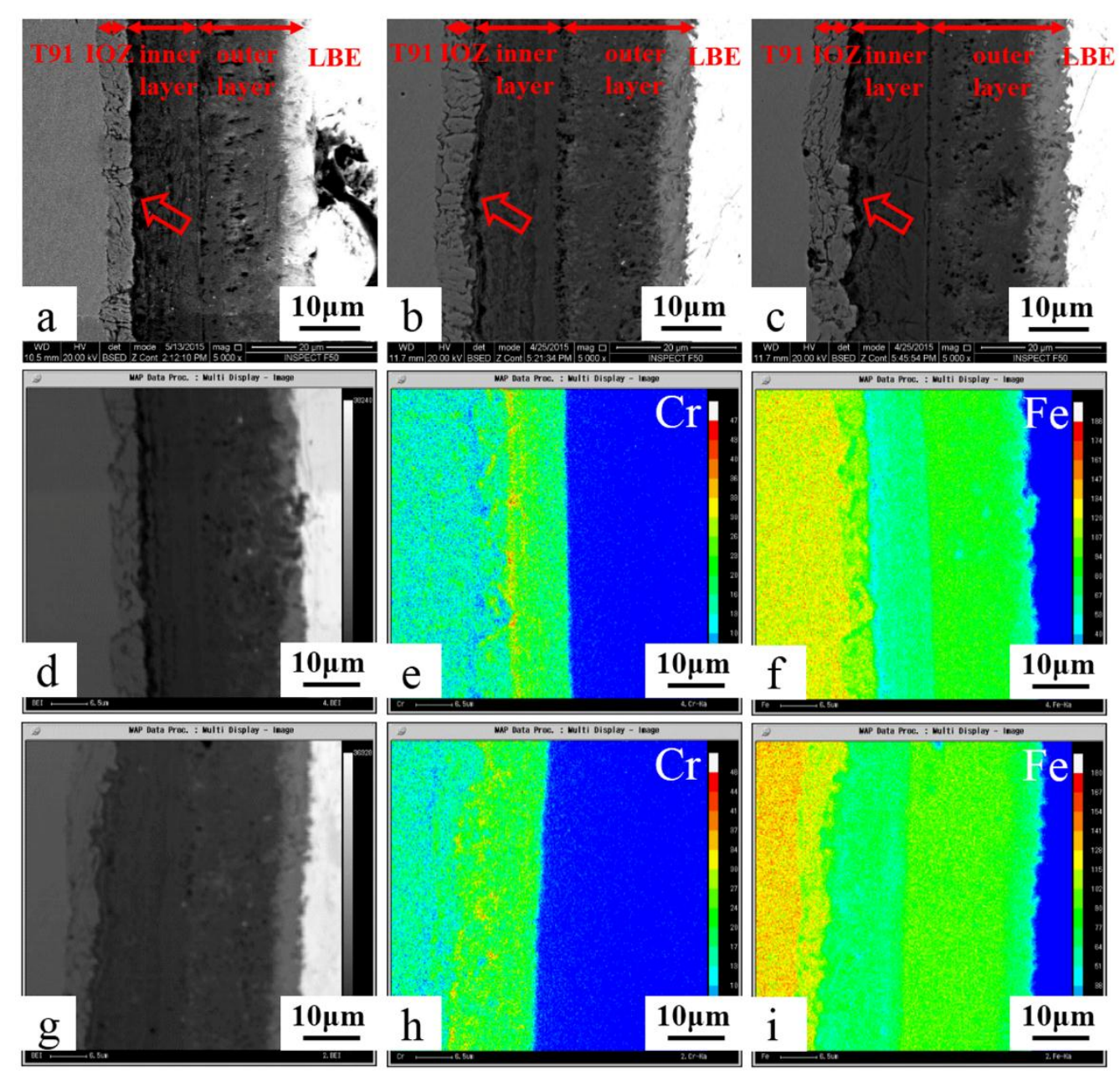

Fig. 2 SEM-BSE and EPMA images of oxide layers after exposure in oxygen-saturated stagnant LBE at $550^{\circ} \mathrm{C}$ for $500 \mathrm{~h}$ (a) SEM image of cold-worked sample, (b) SEM image of tempered sample, (c) SEM image of normalized sample, (d-f) EPMA image of cold-worked sample, (g-i) EPMA image of tempered sample

In order to understand the reasons inducing the continuous enhanced Cr-rich belt in cold-rolled sample, the microstructures of the three samples before and after oxidation test have been observed. Because of the same normalizing temperature and holding time, the prior austenite grain size of them are similar at 20-30 $\mu$ m (Fig. 3a-c). Cold rolling did not induce detectable grain refinement. Although the microstructures of both cold-rolled and tempered samples are tempered martensite without significant difference in SEM observation, the density and morphology of dislocation in them are remarkably different in TEM observation. The dislocation in the cold-rolled sample 
(Fig. 3d) is much more than that in the tempered sample (Fig. 3e). This phenomenon can be attributed to dislocation inheritance caused by the fabrication process of cold-rolled sample [16-17]. The microstructure of normalized sample is martensite and has a much higher dislocation density than cold-rolled and tempered samples due to the martensitic phase transformation (Fig. 3f). HRTEM image reveals that the grain boundaries (GBs) of cold-rolled sample are wavy and corrugated with facets and steps, in particular, many dislocations (marked by $\perp$ in the figure) are piled up near the grain boundary (Fig. 3g). All of these observation are consistent with the description of high-energy non-equilibrium boundaries after severe cold deformation, indicating that the GBs of cold-rolled samples are in a high-energy non-equilibrium state [18-20]. Though there are the highest dislocation density in the interior of grains, the GBs of normalized sample are straight and fewer dislocations are observed in the vicinity of the GBs (Fig. 3h). Thus, the GBs of normalized and tempered samples are considered to be in equilibrium state due to the lack of cold deformation. 

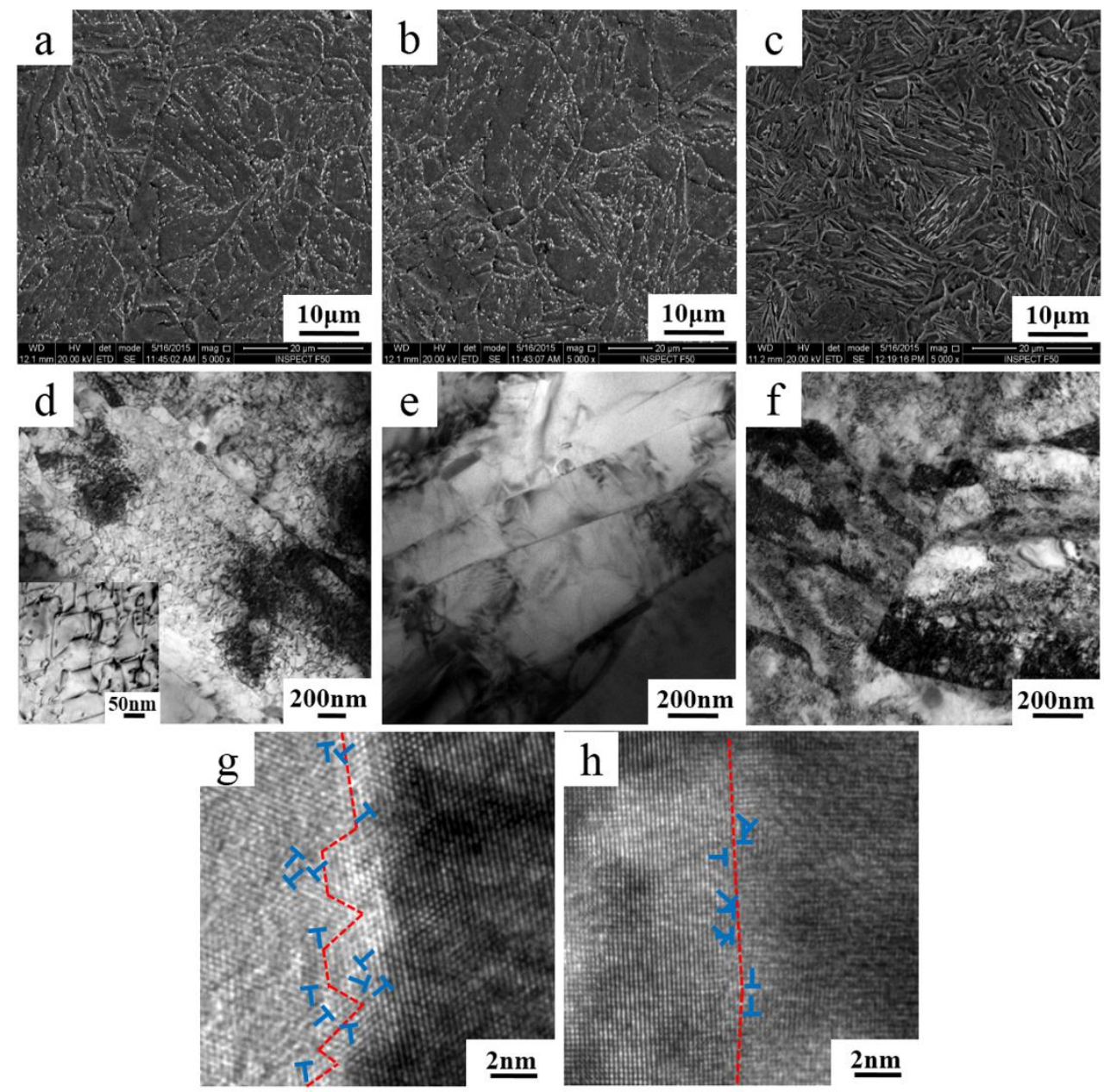

Fig. 3 Microstructures of the samples before oxidation tests: (a) and (d) cold-rolled sample, (b) and (e) tempered sample, (c) and (f) normalized sample, (g) HRTEM image of the grain boundary in the cold-rolled sample, (h) HRTEM image of the grain boundary in the normalized sample

During high temperature oxidation tests the microstructure of samples may change significantly, which in turn influences the oxidation behavior of these samples. Figure 4 shows the microstructure of samples after exposure in $\mathrm{LBE}$ at $550^{\circ} \mathrm{C}$ for $500 \mathrm{~h}$. Because of the aging effect of $550^{\circ} \mathrm{C}$ high temperature, the martensite laths in tempered sample have occurred fragmentation (Fig. 4a). And due to the relatively lower aging temperature, the dislocations in normalized sample have not changed significantly (Fig. 4b). However, the dislocation configuration of cold-worked sample has markedly changed. Dislocation network and dislocation cell structure have 
formed (Fig. 4c and 4d), indicating the dislocations in cold-worked sample have migrated during corrosion test. Additionally, HRTEM image indicates that the GBs in cold-rolled sample after oxidation are still wavy and corrugated with facets and steps. There are dislocations (marked by $\perp$ ) near the wavy GBs. Thereby, the GBs in cold-rolled sample remain in a high-energy non-equilibrium structure after oxidation (Fig. 4e).

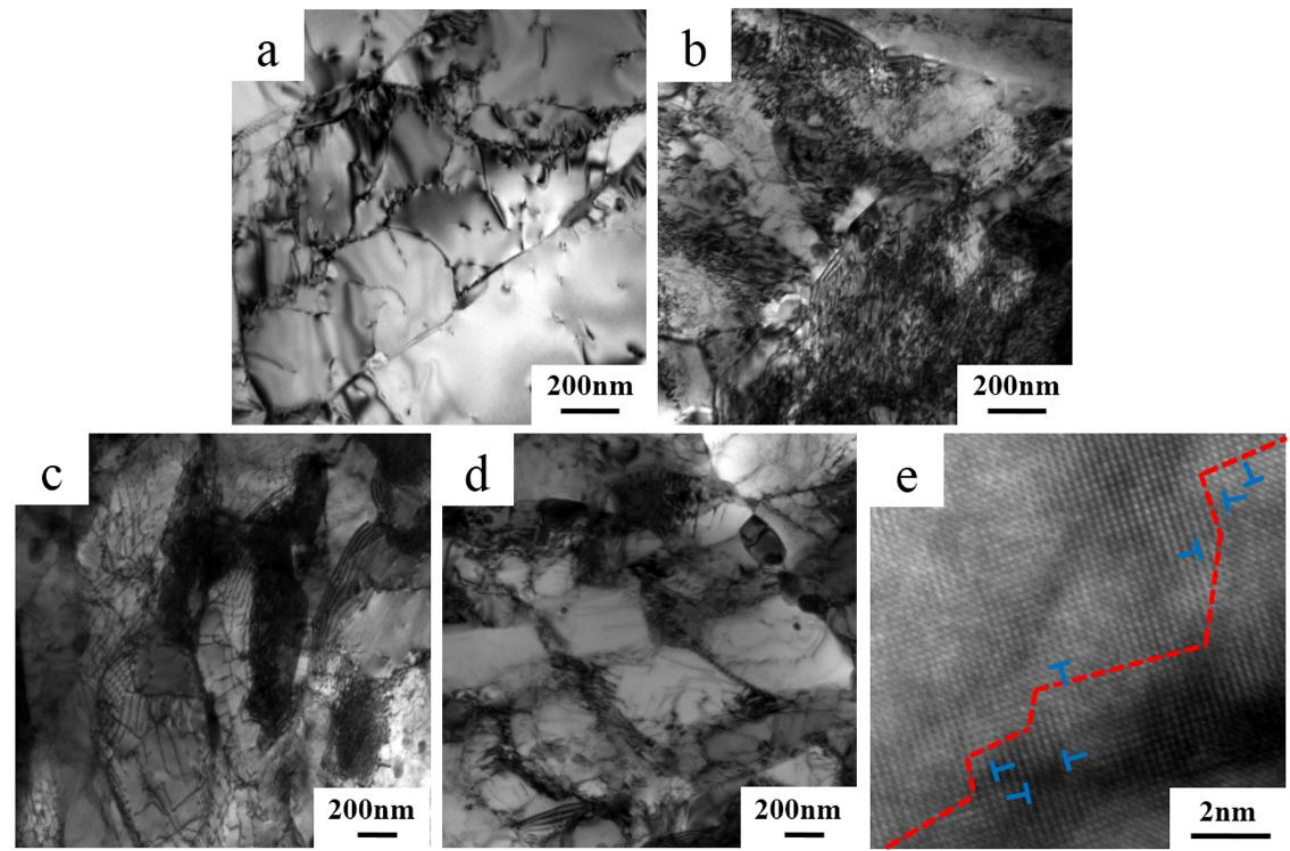

Fig. 4 TEM morphologies of T91 steel after oxidation test in oxygen-saturated stagnant LBE at $550{ }^{\circ} \mathrm{C}$ for 500h: (a) tempered sample, (b) normalized sample, (c) and (d) cold-rolled sample, (e) HRTEM image of the grain boundary in the cold-rolled sample

It is well known that both the dislocations and GBs can act as short-circuit diffusion channels. It has been reported that the diffusion rate in non-equilibrium GBs is 2-4 orders of magnitude higher than equilibrium GBs [21-22]. And the migration of dislocation also can accelerate the diffusion of atom [23]. Therefore, due to numerous non-equilibrium GBs and migrating dislocations induced by the fabrication process of cold-worked sample, the Cr diffusion is accelerated in cold-rolled sample during the high temperature oxidation. The accelerated diffusion of $\mathrm{Cr}$ provides more $\mathrm{Cr}$ into the 
inner layer to form a continuous enhanced Cr-rich belt. On the other hand, in the tempered and normalized samples without non-equilibrium GBs and migrating dislocations induced by cold deformation, the diffusion coefficient of $\mathrm{Cr}$ is low during oxidation tests, although some randomly distributing defects may enhance the diffusion of $\mathrm{Cr}$ locally. Therefore, even though the dislocation density of normalized sample is higher than cold-worked sample, only some scattered and discontinuous enhanced Cr-rich points rather than a continuous enhanced $\mathrm{Cr}$-rich belt was formed in it during the LBE oxidation test.

To conclude, from the above analyses, it is found that the changes of microstructure induced by severe cold deformation is beneficial to improve the oxidation resistance of T91 steel in LBE, although it is not significant. However, this research tells us that the changes of the microstructure of the structural material induced by the manufacture processing may vary the oxidation properties of the material. It is worthy to do more research to use this effect properly in the future.

\section{Conclusion}

The cold-worked T91 sample shows a better oxidation resistance than tempered and normalized T91 samples in oxygen-saturated stagnant $\mathrm{LBE}$ at $450^{\circ} \mathrm{C}$ and $550^{\circ} \mathrm{C}$. The main reason is that numerous non-equilibrium GBs and migrating dislocations induced by severe cold deformation can accelerate the $\mathrm{Cr}$ diffusion, promoting the rapid formation of a protective oxide layer with continuous enhanced Cr-rich belt.

\section{Acknowledge:}

The authors gratefully acknowledge the financial support from the Strategic Priority 
Research Program CAS under Grant No. XDA03010304, National Science Foundation of China under Grant No. 91226204 and the Youth Innovation Promotion Association CAS. The authors also appreciate Dr. Jian Wang gratefully for TEM experiments.

\section{References}

[1] J. Zhang, N. Li, J. Nucl. Mater. 373 (2008) 351.

[2] F.A. Garner, M.B. Toloczko, B.H. Sencer, J. Nucl. Mater. 276 (2000) 123.

[3] T. Auger, G. Lorang, Scr. Mater. 52 (2005) 1323.

[4] K. Lambrinou, V. Koch, G. Coen, J. Van den Bosch, C. Schroer, J. Nucl. Mater. $450(2014) 244$.

[5] C. Schroer, Z. Voß, O. Wedemeyer, J. Novotny, J. Konys, J. Nucl. Mater. 356 (2006) 189.

[6] L. Martinelli, F. Balbaud-Célérier, A. Terlain, S. Delpech, G. Santarini, J. Favergeon, G. Moulin, M. Tabarant, G. Picard, Corros. Sci. 50 (2008) 2523.

[7] L. Martinelli, F. Balbaud-Célérier, A. Terlain, S. Bosonnet, G. Picard, G. Santarini, Corros. Sci. 50 (2008) 2537.

[8] A.K. Rivai, S. Saito, M. Tezuka, C. Kato, K. Kikuchi, J. Nucl. Mater. 431 (2012) 97.

[9] A.L. Johnson, D. Parsons, J. Manzerova, D.L. Perry, D. Koury, B. Hosterman, J.W. Farley, J. Nucl. Mater. 328 (2004) 88.

[10] Y. Kurata, J. Nucl. Mater. 448 (2014) 239.

[11] F. Christien, M.T.F. Telling, K.S. Knight, Scr. Mater. 68 (2013) 506. 
[12] J. Van den Bosch, A. Almazouzi, G. Mueller, A. Rusanov, J. Nucl. Mater. 415 (2011) 276.

[13] T.K. Kim, J.H. Baek, C.H. Han, S.H. Kim, C.B. Lee, J. Nucl. Mater. 389 (2009) 359.

[14] B.F. Gromov, Y.I. Orlov, P.N. Martynov, V.A. Gulevsky, in: Proceedings of Heavy Liquid Metal Coolants in Nuclear Technology-HLMC'98, 1, 1999, p. 87.

[15] J. Bischoff, A.T. Motta, J. Nucl. Mater. 424 (2012) 261.

[16] Z. Yuan, S. Song, C. Li, J. Mater. Sci. Lett. 11 (1992) 1590.

[17] T.Q. Lei, Z.K. Yao, D.Z. Yang, C.Q. Gao, H. Jiang, L.C. Zhao, Thermomechanical Treatment of Metals, China Machine Press, Beijing, 1979.

[18] Z. Horita, D.J. Smith, M. Furukawa, M. Nemoto, R.Z. Valiev, T.G. Langdon, J. Mater. Res. 11 (1996) 1880.

[19] R.Z. Valiev, C. Song, S.X. McFadden, A.K. Mukherjee, R.S. Mishra, Philos. Mag. A $81(2001) 25$.

[20] K. Oh-Ishi, Z. Horita, D.J. Smith, T.G. Langdon, J. Mater. Res. 16 (2001) 583.

[21] R.Z. Valiev, I.M. Razumovskii, V.I. Sergeev, Phys. Status Solidi (a) 139 (1993) 321.

[22] Z.B. Wang, N.R. Tao, W.P. Tong, J. Lu, K. Lu, Acta Mater. 51 (2003) 4319.

[23] R. Naraparaju, H.J. Christ, F.U. Renner, A. Kostka, Mater. High Temp. 29 (2012) 116. 